\title{
Vaginal flatus in women with pelvic floor dysfunction: an observational study
}

\author{
HUI-HSUAN LAU ${ }^{1}$, Chen-Yu Chen ${ }^{2}$, Ying-Yu Chen ${ }^{1}$, Wen-Chu Huang ${ }^{3}$, and Tsung-Hsien \\ $\mathrm{Su}^{1}$
}

${ }^{1}$ Affiliation not available
${ }^{2}$ MacKay Memorial Hospital
${ }^{3}$ Mackay Memorial Hospital

July 27, 2020

\begin{abstract}
Objective To investigate the prevalence of vaginal flatus (VF) in women with pelvic floor disorders and its impact on quality of life. Design A cross-sectional study. Setting A tertiary medical center. Population Women visited a urogynecologic clinic in 2019. Methods Patients were asked about their experience of VF. Other evaluations included urodynamics, genital prolapse stage, and valid questionnaires, including the short form of the Pelvic Organ Prolapse/Urinary Incontinence Sexual Questionnaire (PISQ-12), Urogenital Distress Inventory (UDI-6), and Incontinence Impact Questionnaire (IIQ-7). Clinical characteristics, urodynamic parameters, stage of prolapse, and quality of life scores were compared between women with and without VF. Main Outcome Measures: The impact of VF on quality of life. Results: Among 341 women, 118 (35\%) reported VF, which was more common in those who were younger $(49.3 \pm 9.2$ vs. $59.9 \pm 13.4 \mathrm{yr}, \mathrm{p}<0.001)$ and more sexually active $(98 \%$ vs. $55 \%$, $\mathrm{p}<0.001$ ) women. Women with VF had significantly worse sexual function (PISQ-12, 16.3 \pm 15.9 vs. 30.9 $\pm 8.0, \mathrm{p}<0.001$ ), and incontinence-related quality of life (UDI-6, $23.4 \pm 10.5$ vs. $17.8 \pm 8.9, \mathrm{p}=0.039$; IIQ-7, $25.5 \pm 14.5$ vs. 17.2 $\pm 12.5, \mathrm{p}=0.012$ ). For frequency and bother, $46 \%$ (48/116) of the women reported often or always having symptoms during sexual activity, $15 \%$ (5/34) when performing daily activities, and $12 \%$ (4/31) when exercising; and $60 \%(70 / 116)$ felt least moderate bothersome during sexual activity compared to $5 \%(2 / 34)$ when performing daily activities and $18 \%(6 / 31)$ when exercising. Conclusions: $\mathrm{VF}$ is prevalent in younger and sexually active urogynecologic patients. It has a significantly negative impact on sexual function. Routine counseling should be considered for these patients.
\end{abstract}

\section{Hosted file}

MLC20200722.doc available at https://authorea.com/users/346390/articles/472448-vaginalflatus-in-women-with-pelvic-floor-dysfunction-an-observational-study 